\title{
Interstitial expansion in pressure overload left ventricular hypertrophy
}

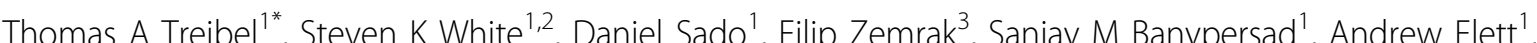
Mark Caulfield ${ }^{3}$, Anna S Herrey ${ }^{1}$, Steffen E Petersen ${ }^{3}$, James Moon ${ }^{1}$

From 16th Annual SCMR Scientific Sessions

San Francisco, CA, USA. 31 January - 3 February 2013

\section{Background}

Diffuse myocardial fibrosis (DMF) is an important factor in cardiac disease, but until recently could only be accurately assessed with biopsy. We hypothesised that DMF measured by Equilibrium contrast CMR (EQ-CMR) is elevated in cardiac pressure overload (hypertension and aortic stenosis), that the degree of DMF will track the clinical severity of pressure overload and cardiac effects, and as such DMF may be a key biomarker in assessing the cardiac effects of pressure overload.

\section{Methods}

ECV measurement was by EQ-CMR. The T1 mapping sequence was ShMOLLI. The contrast agent was Gadoterate meglumine (Dotarem) at $0.1 \mathrm{mmol} / \mathrm{Kg}$ (bolus) plus infusion at 15 minutes at $0.0011 \mathrm{mmol} / \mathrm{kg} / \mathrm{min}$. CMR was at $1.5 \mathrm{~T}$ (Siemens Avanto):

ECV $=(1$-hematocrit $) \mathrm{x}$ (1/T1)myo $\div$ (1/T1)blood.

ECV was measured in 43 patients with isolated, wellcontrolled hypertension (median age 56, range 21 to 78 , $55 \%$ male), 28 patients with severe aortic stenosis (AS) undergoing aortic valve replacement (median age 70, range 60 to $84,71 \%$ male), and 50 healthy volunteers (median age 47 , range 28 to $69,58 \%$ male).

\section{Results}

ECV measurements were the lowest in the control group with significantly higher ECV values in hypertension and AS (0.261 versus 0.274 versus $0.296, p \leq 0.02$; Figure 1 ).

The mass index increased from normal to hypertension to AS $\left(66 \mathrm{~g} / \mathrm{m}^{2}\right.$ versus $85 \mathrm{~g} / \mathrm{m}^{2}$ versus $101 \mathrm{~g} / \mathrm{m}^{2}, \mathrm{p}<0.05$; Figure 2), whereas the indexed left atrial area was only significantly higher in AS $\left(11.0\right.$ and $11.6 \mathrm{~cm}^{2} / \mathrm{m}^{2}$ versus $\left.13.2 \mathrm{~cm}^{2} / \mathrm{m}^{2}, \mathrm{p}<0.05\right)$; end-systolic and diastolic volumes were not significantly different among cohorts.

\section{Conclusions}

The myocardial ECV increases with the degree of left ventricular pressure overload hypertrophy.

\section{Funding}

British Heart Foundation; National Institute for Health Research.

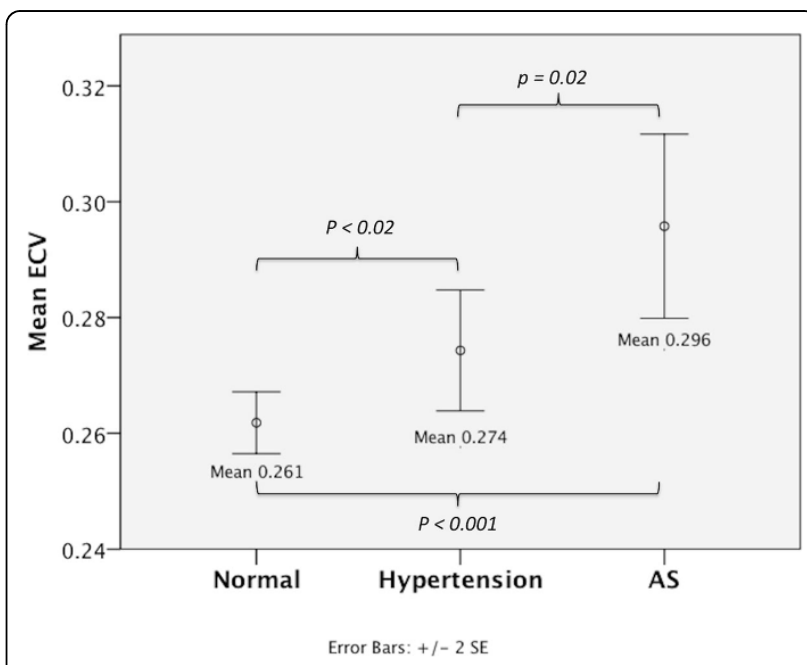

Figure 1 ECV measurements by EQ-CMR were the lowest in the control group with significantly higher ECV values in hypertension and aortic stenosis $(0.261$ versus 0.274 versus $0.296, p \leq 0.02$ ) 


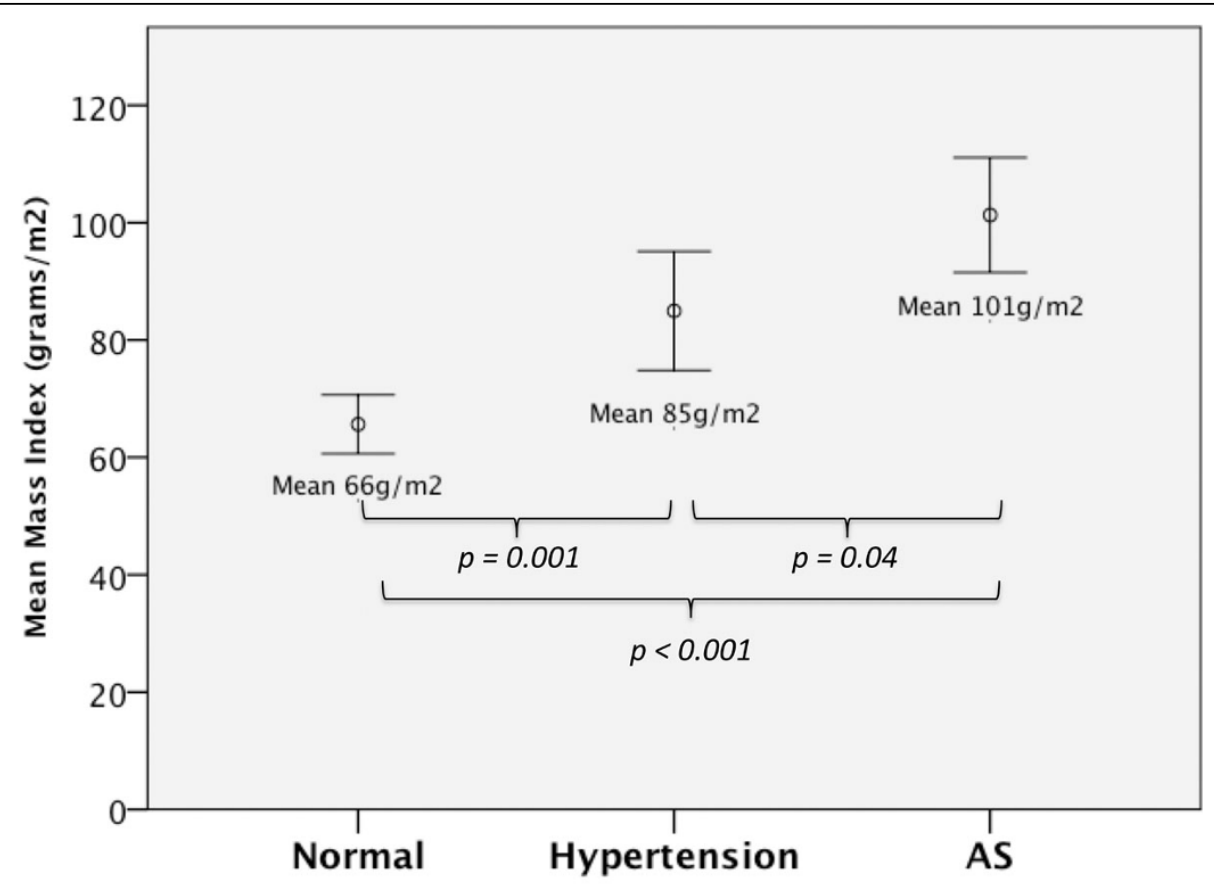

Error Bars: + /- 2 SE

Figure 2 The left ventricular mass index increased from normal to hypertension to aortic stenosis $\left(66 \mathrm{~g} / \mathrm{m}^{2}\right.$ versus $85 \mathrm{~g} / \mathrm{m}^{2}$ versus $101 \mathrm{~g} / \mathrm{m}^{2}$, $p<0.05)$.

\section{Author details}

'The Heart Hospital Imaging Centre, University College London, London, UK. ${ }^{2}$ The Hatter Cardiovascular Institute, University College London Hospitals NHS Trust, London, UK. ${ }^{3}$ Cardiovascular Biomedical Research Unit, Barts and the London School of Medicine and Dentistry, Queen Mary University of London, London, UK.

Published: 30 January 2013

doi:10.1186/1532-429X-15-S1-092

Cite this article as: Treibel et al: Interstitial expansion in pressure overload left ventricular hypertrophy. Journal of Cardiovascular Magnetic Resonance 2013 15(Suppl 1):O92.

Submit your next manuscript to BioMed Central and take full advantage of:

- Convenient online submission

- Thorough peer review

- No space constraints or color figure charges

- Immediate publication on acceptance

- Inclusion in PubMed, CAS, Scopus and Google Scholar

- Research which is freely available for redistribution

Submit your manuscript at www.biomedcentral.com/submit 